Fernando Cid Lucas

AEO. Universidad Autónoma de Madrid

\title{
NOH JAPONÉS MODERNO DE TEMÁTICA CRISTIANA: ¿UN GUIÑO AL TEATRO MEDIEVAL IBÉRICO?
}

\author{
Al hermoso Japón \\ que yace ahora bajo los escombros.
}

Palabras clave: misterio, Noh, teatralización

\section{Japón: país cristiano}

Mucho y bueno se ha escrito ya sobre la llegada del Cristianismo a tierras japonesas a mediados del siglo XVI ${ }^{1}$. Cada vez son más abundantes las monografías, los capítulos de libros o los artículos referentes al navarro san Francisco Javier (1506-1552) y a su labor evangelizadora en el País del Sol Naciente ${ }^{2}$, lo mismo que sobre quienes le siguieron en los tempestuosos años posteriores a su marcha de Japón hacia el continente.

En efecto, fue él quien primero llevase hasta allí la palabra del dios cristiano, y fue también el primero en trabajar fervorosamente por y entre los japoneses. Un trabajo que, a pesar de lo breve que resultó en la línea del tiempo, dio, sin embargo, frutos muy tempranamente. Y resultó ser ésta una labor - por lo que se desprende de la lectura de las muchas cartas del santo navarro redactadas en el archipiélago nipón- hecha desde el amor y el profundo aprecio hacia aquel pueblo recién descubierto por los europeos. Sirva como ejemplo de lo que digo un párrafo de la muy conocida carta escrita a sus compañeros jesuitas asentados en Goa: «[...] Es la mejor que hasta ahora se ha descubierto; y me parece que entre gente infiel no se hallará otra que gane a los japoneses [...]» (Leonardi, 2000: 870).

Fue el 15 de agosto de 1549, seis años después de que unos náufragos lusos arribasen a Japón por azar, cuando llegaba el Apóstol de las Indias a Kagoshima (en la sureña isla de Kyūshū); pondría allí, no sin dificultades, toda su alma y todos sus esfuerzos por evangelizar el País del Sol Naciente durante sus siguientes veintisiete meses de ininterrumpida estadía.

Sus logros en Japón fueron muchos y diversos (igual que sus fracasos, dirán algunos autores): se ocupó de que se tradujesen algunos textos que habrían de servir para sustentar

\footnotetext{
Pongo como ejemplos: Cabezas García, Antonio, El siglo ibérico en Japón: la presencia hispano-portuguesa en Japón (1543-1643), Universidad de Valladolid, Valladolid, 1990; Sola Castaño, Emilio, Historia de un desencuentro. España y Japón 1580-1614, Alcalá de Henares, Fugaz, 1999; o Takizawa, Osami, La historia de los jesuitas en Japón, Universidad de Alcalá de Henares, Alcalá de Henares, 2010.

2 No me resisto a incluir aquí la reciente e interesantísima publicación debida a: García Valdés, Celsa Carmen (ed.), Coloquio de la conquista espiritual del Japón hecha por San Francisco Javier, Servicio de Publicaciones de la Universidad de Navarra, Pamplona, 2010.
} 
la fe de los nipones, como la Declaración de los capitulos de Fe, de Fray Luis de Granada, que Javier sabía al dedillo en japonés y que lo empleaba en sus predicaciones; y, según las fuentes, para el año 1570, gracias al influjo inicial del navarro, los cristianos en Japón no serían menos de unos treinta mil (Gardini, 1995: 160).

Tras su salida hacia el continente, donde encontraría la muerte víctima de unas terribles fiebres, Japón viviría un breve pero intenso idilio con el Cristianismo. Grandes hombres de fe, como Alessandro Valigniano o Diego Collado, trabajaron allí de manera entregada, y muchos fueron los mártires hechos en tierras japonesas durante las consecutivas persecuciones ${ }^{3}$. Con el decreto definitivo de expulsión y con el celoso acecho a los cristianos, sólo una pequeña porción de los convertidos perdurará oculta (otros muchos renegarían de su fe, habrían escapado a países vecinos o habrían muerto por orden expresa del shōgun), y fue sólo tras la reinstauración Meiji (1868) cuando se descubriese la peculiar forma de Cristianismo que se había conservado de manera secreta en esos lares; una forma en la que se mezclaban sincréticamente las creencias budistas y shintoistas e interpretaciones particularísimas de la doctrina cristiana ${ }^{4}$. El profesor Federico Lanzaco, ex jesuita y buen conocedor de la realidad religiosa del Japón de ayer y de hoy, en el texto de su impecable conferencia titulada: Un siglo de comercio y evangelización por España-Portugal en el Extremo Oriente a través de las dos rutas marítimas del Patronato Español (Sevilla, Acapulco, Manila, Japón) y del Padroado Portugués (Lisboa, Cabo Buena Esperanza, Goa, Macao, Nagasaki) (1543-1636), nos dice al respecto: «[...] Sin la ayuda de ningún sacerdote ni apoyo de misioneros algunos del exterior conservaron su fe cristiana en secreto. Su número pudo ser de unos diez mil fieles, pobres pescadores y campesinos de Kyushu $[\ldots]^{5} . »$

Como indicaba, fue sólo con la apertura de las fronteras japonesas al resto del mundo cuando los cristianos retornaron otra vez al país que tanto amase Francisco Javier. Sin embargo, ahora los españoles y los portugueses quedarían muy a la zaga en cuanto a influencias religiosas se refiera, en detrimento de diferentes ramificaciones del protestantismo inglés y norteamericano; aunque nuevas iglesias y congregaciones religiosas católicas, apostólicas y romanas, surgiesen al calor de ciudades como Tokyo, Hiroshima o Nagasaki, urbes estas dos últimas, empero, poseedoras de una rancia tradición cristiana.

Pero no es mi intención trazar aquí una historia (ni siquiera breve) del Cristianismo en tierras niponas, de eso ya se encargaron y se están encargando mejor que yo grandes especialistas en esta materia ${ }^{6}$, sino que mi única pretensión es la de traer y presentar al

\footnotetext{
Para este asunto véase: Takizawa, Osami, «El testimonio de los mártires cristianos en Japón (1559-1650)», Boletín de la Asociación Española de Orientalistas, 2008, pp. 79-98.

4 Un ejemplo curioso es que estas comunidades creyesen que Poncio Pilatos fuesen dos personas diferentes: Poncio y Pilatos. Para saber más sobre este interesante asunto, léase: Turnbull, Stephen, The Kakure Kirishitan of Japan: A Study of Their Development, Beliefs and Rituals to the Present Day, Routledge Curzon, London/New York, 1998.

5 Texto íntegro disponible en: http://www.uatatumi.org/lanzaco.pdf.

6 Me consta que, entre otros, el profesor Eduardo Javier Alonso Romo, de la Universidad de Salamanca, o la profesora Carla Tronú Montane, de la Universidad Autónoma de Madrid, están centrando sus investigaciones en esta apasionante parcela dentro de las relaciones entre la Península Ibérica y Japón.
} 
lector varias obras de teatro Noh -elaboradas todas en tiempos relativamente recientescuyas temáticas beben de manera directa de las fuentes cristianas, mas se encuentran profundamente imbricadas por el espíritu y por la estética japonesa que las enmarca. A continuación, pasaremos a describir con más detalles lo que ahora digo.

\section{Literatura japonesa y Cristianismo}

Apenas en unos pocos párrafos me referiré a la relación que han tenido varios autores nipones con la religión cristiana, minoritaria ${ }^{7}$ con respecto al Shintoísmo vernáculo o al importado Budismo (incluso frente a las religiones de nuevo cuño en su conjunto ${ }^{8}$ ). Basta decir que todos los géneros literarios se han visto influenciados en Japón por el Cristianismo, y todos han sido «tocados» por esta religión de una u otra forma. Por su brevedad (y su intensidad) no me resisto a incluir aquí un vibrante haiku del maestro Shiki Masaoka (1867-1902). Dice así:

\section{牡丹咲く浄土の寺の絵踏みかな}

Botan saku Jōdo no tera no ebumi kana

Lo que podríamos traducir al español, no sin problemas, por:

Mientras florece la peonia

en el templo de Jōdo

pisan el icono cristiano?.

Magistral composición poética donde, en apenas tres versos, su autor nos retrata una imagen que hubo de repetirse miles de veces durante el denominado «Siglo Ibérico de Japón»: la de los ciudadanos nipones que, como prueba de su no pertenecía a la religión llevada hasta allí por los europeos, debían pisar, en señal de renuncia, una efigie de Cristo o de la Virgen María fabricada en metal y madera. En ocasiones, tal prueba tenía lugar en los aledaños de templos shintoístas o budistas, como el de Jōdo, tal y como recoge Shiki en su conmovedor haiku.

Y, si en una forma tan popular (ya también en Occidente) como el haiku resuenan los ecos del Cristianismo, la novelística no iba a ser menos. Ahora presento al lector sólo dos buenos ejemplos que han tenido traducciones ya a idiomas occidentales y que han cosechado cierto éxito de crítica: Chinmoku (Silencio) y Jesu no Shôgai (La persona de Jesu-

Serían 2.161.707 en 2004, según recoge el profesor Alfonso Falero en su trabajo: «Religiones japonesas y globalización», ¿Qué es Japón? Introducción a la cultura japonesa (ed. Fernando Cid Lucas), Servicio de Publicaciones de la Universidad de Extremadura, Cáceres, 2009, p. 25.

8 Véase para esto el artículo de: Vofchuk, Rosalía C., «Las nuevas religiones del Japón Moderno. La importancia del Sutra del Loto (II)», Boletín de la Asociación Española de Orientalistas, 39, 2003, pp. 243-256.

9 Ebumi o, más corrientemente transcrito, fumie, era la imagen que se hacía en cobre u otro material en donde se representaba a la Virgen María o a Cristo, que los esbirros del gobierno Tokugawa hacían pisar a los japoneses para comprobar si eran cristianos o no. Naturalmente, si se abstenían de hacerlo delataban su condición y eran apresados y castigados de inmediato. 
cristo), ambas salidas de la pluma del escritor de fe cristiana Shūsaku Endō (1923-1996). Acaso la más conocida y difundida en Occidente haya sido la primera de las dos (tal vez en esto influyó la brillante adaptación cinematográfica que de ella hiciera en 1971 el director Masahiro Shinoda), que en España se publicó en una elegante traducción debida a los jesuitas Jaime Fernández S. J. y José Miguel Vara S. J. ${ }^{10}$

En sus páginas, llenas de reflexiones sobre el Cristianismo y su lugar en Japón y entre los japoneses, aparece otra vez el periodo de intensas y sostenidas persecuciones y las torturas que debieron soportar los cristianos nipones y los religiosos europeos destacados allí. Una novela que, en definitiva, retrata una época llena de luces y sombras en las relaciones entre Japón y Occidente, que, incluso, ha movido a cineastas de la talla de Martin Scorsese a realizar una nueva adaptación de la novela de Endō (aunque, a día de hoy, la noticia sigue siendo un rumor $)^{11}$.

\section{El Noh y los misterios medievales}

Antes de comenzar a analizar en profundidad la obra que nos ocupa en este artículo, se hace necesario dar unas pocas pinceladas sobre el excelso arte que sigue siendo el teatro Noh, ya que -y aunque varios estudios se han publicado hasta ahora en nuestro idio$\mathrm{ma}^{12}$ - sigue siendo, como el resto de las artes escénicas japonesas, un gran desconocido en nuestros parámetro geográficos.

El Noh no es un espectáculo cualquiera; fue, durante siglos, un refinado arte destinado a las clases altas de la sociedad japonesa (aristócratas, religiosos y samuráis), en el que se mezclaba la mejor poesía, la danza y la música. En su poética definitiva influirían notablemente las danzas y los rituales shintoístas (Okina mai, Kagura, etc.) y diversos tipos de bailes y músicas de índole noble y villana (Gigaku, Bugaku o Sarugaku ...), algunos traídos desde Corea, China o la lejana India. Como decía, por mucho tiempo fue un espectáculo feudo exclusivo de nobles, cortesanos y guerreros, quienes actuaron como sus mecenas y patrones durante siglos.

Entrando ya en materia, una de las coincidencias sustanciales que encontramos entre el Noh y los misterios es que sendos espectáculos dan muestras de una estilizada sobriedad. Así, tanto en nuestro teatro medieval como en el Noh reina un halo de sostenido recogimiento, materializado, sin duda, en una escena construida únicamente con los elementos escenográficos mínimos necesarios. No hablamos ahora, pues, de un teatro hecho con grandes decorados o que precise de complicadas maquinarias para su funcionamiento. Esto será propio de espectáculos más tardíos en sendas cronologías teatrales: del Kabuki en el País del Sol Naciente y del teatro del corral de comedias en la Península Ibérica.

10 Primero publicada en: Atenas-Sígueme, Salamanca, 1973; luego en: PPC, Madrid, 1976; y, finalmente, en: Edhasa, Barcelona, 1988 ( $1^{\mathrm{a}}$ ed.) y 2009 ( $2^{\mathrm{a}}$ ed.).

11 Se ha barajado, incluso, que el actor español Javier Bardem sería el elegido para encarnar el papel del protagonista, el atormentado jesuita Sebastián Rodrigues.

12 Rubiera, Javier e Higashitani, Hidehito, Fūshikaden. Tratado sobre la práctica del teatro Nō y cuatro dramas Nō, Trotta, Madrid, 1999; y Takagi, Kayoko y Janés, Clara, 9 piezas de teatro Nô, Ediciones del Oriente y del Mediterráneo, Madrid, 2008. 
Tal vez porque su esencia reside en el contenido de sus guiones ${ }^{13}$, los dramaturgos (que en Japón actuaron también como coreógrafos y directores de escena) de uno y otro lado del mundo maduraron «aislar» al actor y a su mensaje frente al público. Permítame el lector, sin embargo, matizar esta palabra que entrecomillo, ya que, por ejemplo, la música (y la danza, en el caso de Japón) fue importante a la hora de ejecutar las obras. La palabra declamada y cantada contaba con un importante soporte musical, aunque $-\mathrm{y}$ vuelven las semejanzas- los tonos de composición armónica se encontraban supeditados a la forma de entonar los parlamentos de los diferentes personajes.

En cuanto al dramatis personae, tampoco éstos solían ser abultados, no concurriendo sobre las tablas más de dos o tres actores por cada escena; un ejercicio con el que se facilitaba la comprensión de los diálogos que pronunciaban los actores, que, por otra parte, tampoco se entremezclaban demasiado, siendo estos textos claros y muy directos, aunque, en ocasiones, se emplease un estilo muy poético, pero sin perderse nunca en demasiada retórica o en parlamentos largos o enrevesados.

Por lo que se refiere al lugar de la representación, huelga decir que los misterios medievales ibéricos eran ejecutados siempre en el interior o en las inmediaciones de las iglesias (plazas, atrios ...). Y también en Japón encontrará el Noh (como su antecesor, el Kagura) un lugar en los templos shintoistas y budistas, en los que las funciones de Noh formaban parte de los festivales y de las celebraciones en loor del kami local o de los rituales búdicos del lugar. No en vano, y como ya he explicado en otros artículos ${ }^{14}$, la temática religiosa cobra gran relevancia en el Noh, en obras tan representativas como Takasago o Uzume, en las que aparecen, nada menos que los mismos dioses de la tradición shintoísta; y en otras, como la titulada Ikaku Sennin, emanaciones del mismo Buda o santones seguidores de alguna rama de la religión fundada por el príncipe Siddhartha. Sobra decir también que los parlamentos que los dramaturgos otorgan a estos personajes son siempre medidos, y que los preceptos religiosos se funden en armonía con la acción teatral.

En lo tocante a los actores, y aunque las protagonistas de algunas piezas sacras ibéricas sean mujeres, lo mismo que en la obra de Noh de la categoría onna-mono, todos los papeles serán encarnados por varones. Por niños, tal y como se apunta, por ejemplo, en las diferentes versiones de las Visitatio, en nuestro país, y por hombres, como marca la centenaria tradición del Noh en el País del Sol Naciente.

Asimismo, tradicionalmente, las representaciones teatrales tenían lugar durante conmemoraciones especiales. En la Península Ibérica se hacían durante la Pascua o la Navidad, mientras que en Japón se programaban para formar parte de diferentes festivales (matsuri) o conmemoraciones dedicadas a la familia imperial o a la del shōgun.

\section{Noh con temática cristiana}

Antes de hablar de títulos, es de rigor indicar que fue el jesuita japonés y profesor en la Universidad de Sophia Kakichi Kadowaki (1926) quien primero empleó en la cele-

13 Muy sabiamente complementados con la música y el canto.

${ }^{14}$ Cid Lucas, Fernando, «Trazas religiosas (shintoístas, budistas y taoístas) en el teatro Noh: cuando el precepto se hace danza», BANDUE: Revista de la Sociedad Española de Ciencias de las Religiones, 5, 2011 (en prensa). 
bración de las homilías dominicales el Noh, imbricando el rito cristiano con el shintoísta/ budista. Como dramaturgo, fue coautor, junto con Sugiura Tsuyoshi, también profesor en la citada universidad, de la pieza Iesu no senrei (El bautizo de Jesús), en donde se escenificaba este crucial momento de la vida de Cristo. En solitario compuso Kakichi Azumi no mi-haha (La Virgen en Azuchi), que se estrenó en 1990 y cuyo shite (personaje protagonista) es la Virgen María.

Amén de la pieza que ahora estudiaremos con mayor detenimiento, han sido ya varias las obras escritas para teatro Noh con argumento cristiano que se han representado en los escenarios japoneses y que han provocado, incluso, un pequeño número de trabajos críticos. De una de ellas, la titulada Nagasaki no Seibo (La Santa Madre de Nagasaki), se ocupó magistralmente el jesuita Diego Pacheco S. J. en su artículo titulado: Nagasaki: teatro Noh en la catedral ${ }^{15}$. En esta pieza, el shite vuelve a ser la mismísima Virgen María, quien habría descendido a la tierra para ayudar a los numerosos heridos provocados por la terrible y destructora bomba nuclear de Nagasaki. Su primera representación tuvo lugar, nada menos que en la nave central de la catedral de la citada ciudad japonesa. En ella, su autor, Tomio Tada (1934-2010), inmunólogo de profesión, aúna una de las marcas culturales del Japón, el Noh, con su fe, consiguiendo un hermoso y nada forzado ejercicio de interculturalidad.

Una obra muy poco conocida, incluso entre los propios japoneses, tiene su argumento en la cruenta Rebelión de Shimabara (Shimabara no Ran), que tuvo lugar entre los años 1637-1638. En ella se enfrentaron los hombres del shōgun a algunos señores feudales bautizados en el cristianismo. El shite de esta obra, compuesta por miembros de la añeja casa Kanze, que se estrenó en 1995, no es otro que el noble japonés cristiano Masuda Shirō Tokisada (¿1621?-1638), quien muy joven descubrió la religión católica y defendería el castillo Hara, bastión cristiano recuperado a los Tokugawa, en donde encontrará la muerte junto a otros muchos compañeros.

Para terminar esta breve lista de obras teatrales con temática cristiana, otro gran maestro de Noh, perteneciente a la escuela Kita ${ }^{16}$, Minoru Kita (1900-1986), escribió y coreografió una pieza con idéntico argumento a Fukkatsu no Kirisuto, titulada, simplemente, Fukkatsu (Resurrección), que no debemos confundir con la que analizaremos a continuación.

De todas ellas podemos decir, sin temor a equivocarnos, que tienen un fin eminentemente catequizador, y también que buscan un público principalmente japonés para mostrar los puntales de la fe cristiana. Lo mismo que hacía el teatro litúrgico medieval, que sirvió «como instrumento de educación y formación del pueblo cristiano» (Castro, 1997: 48). Sin embargo, si el auditorio en las iglesias y catedrales ibéricas, en esencia, estaba constituido por gentes del pueblo, en Japón lo formaron, hasta mediados del siglo XIX, los nobles y aristócratas.

15 Pacheco, Diego, «Nagasaki: teatro Noh en la catedral», Temas de Estética y Arte, 20, 2006, pp. 185-196.

${ }^{16}$ La más reciente de entre las cinco grandes casas o escuelas de Noh: Kanze, Komparu, Kongō, Hōshō y Kita. Ésta nació a principios del periodo Edo, alrededor del año 1619. 


\section{Un caso paradigmático: Fukkatsu no Kirisuto}

Podemos afirmar que, por su argumento, Fukkatsu no Kirisuto (Cristo Resucitado) es una pieza anómala en el repertorio del Noh contemporáneo. Escrita por un conjunto de personalidades relacionadas con el teatro más sublime de Japón, el Noh queda aquí representado por uno de sus últimos grandes artífices, el actor Hōshō Kurō, junto a una pequeña nómina de grandes expertos en teología cristiana radicados todos ellos en Japón, como el jesuita alemán Herman Heuvers S. J. ${ }^{17} \mathrm{o}$ el profesor Muto Tomio ${ }^{18}$.

El presente análisis, sin embargo, se efectuará desde la traducción al inglés que del original japonés efectuase Fumio Otsuka, hijo de un famoso actor de Noh natural de la ciudad de Osaka y actor él mismo de esta variedad escénica, aunque la versión final de la pieza se deba al profesor Richard Taylor, quien la publicó de manera íntegra, acompañada de una introducción y una coda (Taylor, 1971).

Como las diferentes Visitatio Sepulchri que se nos han conservado, Fukkatsu no Kirisuto está construida a partir del Evangelio de San Lucas (24: 1-9), en concreto sobre el momento en el que María Magdalena, Juana y otras mujeres van a visitar la tumba de Jesús para olear su cuerpo con aceites y otros ungüentos y descubren que la roca que tapaba el sepulcro está descorrida. En el interior están las vendas y las telas que envolvían el cuerpo de Cristo, pero no hay rastro alguno de éste. En esos momentos de desconcierto, unos ángeles se aparecen en el lugar y conversan con las mujeres.

Será María Magdalena, erigida como portavoz de las mujeres, quien comienza la obra, ubicando al espectador y anunciando qué es lo que van a hacer allí los personajes:

[...] As the light broke,

We woke from our dream,

Impelled to seek

The resting place of our Master. [...]

El texto continúa hermosamente, guiando con palabras muy concisas al público, que se ve transportado a la boca misma de la cueva que albergó el cuerpo inerte de Jesús. Una vez allí, y como decía, las mujeres encontrarán descorrida la piedra que sellaba la cueva, lo que sorprende a la Magdalena y a las otras mujeres.

$\mathrm{Al}$ igual que en las diferentes variantes de las Visitatio Sepulchri, hay espacio en los textos para recalcar cuáles son las intenciones de las mujeres allí, y si en versiones como la de Vic se resalta el pasaje de la compra de la mirra:

Sed eamus unguentum emere,

quo possimus corpus inungere;

17 Aunque en el texto en inglés aparezca como H. Hoivels seguramente se trató de un error a la hora de transcribir a romanji. Según me dice mi querido amigo, el profesor Jaime Fernández, de la Universidad de Sophia, el padre Heuvers nació en Alemania en 1890, cuando falleció en 1977 estaba ayudando como sacerdote en la parroquia de San Ignacio, que está al lado de la Universidad de Sophia en Tokyo.

18 Autor y coordinador de varias obras teóricas sobre el Cristianismo en Japón o sobre pensadores nipones cristianos. Durante un tiempo fue editor de la prestigiosa revista Kirisuto Shimbun. 
non amplius poscet putrescere.

Heu, [quantus est noster dolor!]. (Castro, 1997: 124)

Del mismo modo, nos dirá María Magdalena en Fukkatsu no Kirisuto:

It is the first day of the week, and, carrying sweet spices,

we hurry to the tomb before sun-rise.

Uno de los rasgos más interesantes que comparten los textos dramáticos medievales y la obra de Noh en cuestión es la intensa emoción que hallamos en el encuentro de las mujeres con el ángel, delatando ya su naturaleza litúrgica y, tal vez, buscando cierto efectismo emocional entre el auditorio. Así, tras descubrir con asombro que la roca se ha movido -y con el turbador efecto que esto produce en las mujeres- la voz del ángel les anuncia que aquél al que van a buscar ya no se encuentra allí. Una escena que logra que se nos estremezca y encoja el corazón:

\author{
(High) Why do you look \\ for the living among the dead? \\ $\mathrm{He}$ is risen; He is not here: \\ Behold the place \\ where they laid Him.
}

Palabras que coinciden con las que, según el Evangelio de Lucas, pronunciaron los hombres de «ropas fulgurantes» al advertir la presencia de las mujeres en la oquedad: «¿Por qué buscáis entre los muertos al que vive? No está aquí, ha resucitado.» Versos (los japoneses) que, en mi opinión, acometen frontalmente el Evangelio, realizando una teatralización de los mismos que recae en un sólo personaje y en un sólo pasaje, al contrario de lo que sucede, por ejemplo, en la Visitatio Sepulcri de Silos, donde se añade, además, que los portadores de tal noticia son los ángeles (celicole):

[...] Interrogat angelus et dicat ad discipulos

Quem queritis in sepulcro hoc, cristicole?

Respondent discipuli et dicant

Jhesum Nazarenum crucifixum, o celicole.

Iterum respondet angelus

Non est hic. Surrexit sicut loquutus est.

Ite, nunciate quia surrexit Dominus.

Alleluia. [...] (Castro, 1997: 162)

Otro tanto sucede en la hermosa versión de Vic, a la que ya nos hemos referido:

[...] Respondet Angelus

Quem queritis in Sepulchro, cristicole? 
$\mathrm{R}$ [espondet] Maria

Ihesum Nazarenum crucifixum, o celicole.

$\mathrm{R}$ [espondet] Angel <us $>$

Non est hic; surrexit sicut predixerat.

Ite, nunciate quia surrexit, dicentes:

Respondet Mari $<\mathrm{a}>$

Alleluia. Ad sepulchrum residens

Angelus nunciat resurrexisse Christum.

TE DEUM LAUDAMUS [...] (Castro, 1997: 132)

Avanzando en la obra de Noh (y aunque no podamos retratar aquí las fundamentalísimas partes danzadas y cantadas que acompañan a las palabras), será María Magdalena la que vuelva a tener la voz principal entre las mujeres, y la que confiesa la dureza de sus días tras la pérdida del rabí. En cortos y concisos versos se expresa la de Magdala con extrema dulzura, con el anhelo de quien ha perdido una parte importante de su mismo ser:

FIRST TSURE (Weak and low): Bleak is our path Without Him; [...]

Un testimonio que se opone, por ejemplo a la entereza con la que se muestra María Magdalena en los evangelios apócrifos, como en el denominado Evangelio de María, en donde aparece casi como adalid del difunto Jesús, arengando a los apocados discípulos una vez ha desaparecido el maestro, y quien se encarga, además, de reconfortarlos. Traslado ahora un pequeño fragmento del texto aludido:

[...] Ellos, sin embargo, estaban entristecidos y lloraban amargamente diciendo: «¿Cómo iremos hacia los gentiles y predicaremos el evangelio del reino del hijo del hombre? Si no han tenido con él ninguna consideración, ¿cómo la tendrán con nosotros?» Entonces Mariam se levantó, los saludó a todos y dijo a sus hermanos: «No lloréis y no os entristezcáis; no vaciléis más, pues su gracia descenderá sobre todos vosotros y os protegerá. Antes bien, alabemos su grandeza, pues nos ha preparado y nos ha hecho hombres.» Dicho esto, Mariam convirtió sus corazones al bien y comenzaron a comentar las palabras del [Salvador] $[\ldots]^{19}$.

Sin embargo, las múltiples variantes medievales del misterio presentan a las mujeres indefensas, compungidas y afligidas, accionadas sólo por la palabras de los ángeles, y con poca o ninguna iniciativa propia.

El clímax de la obra de Noh vendrá cuando el shite ${ }^{20}$ (Cristo) haga su triunfal entrada en escena, luego de pronunciar algunas palabras desde el exterior del escenario; un recur-

${ }_{19}$ En: http://escrituras.tripod.com/Textos/EvMagdalena.htm

${ }^{20}$ Actor principal que junto al waki (deuteragonista) forman el binomio fundamental en la nómina de actores del Noh. 
so que servirá para poner sobre aviso al público acerca de que algo importante va a pasar en unos momentos, de que alguien va a entrar a escena:

[...] What sounds are these

From in front of the tomb? [...]

Justo después, el actor que encarna a Jesús ejecutará el denominado sashi (サシ), un canto en verso de un gran lirismo y profundidad en el que desgranará uno o varios pensamientos interiores, o mediante el que nos informará de su cometido allí o su propia identidad. En el caso que nos ocupa, de sus labios saldrán datos como:

\section{$[\ldots]$ I am resurrected $[\ldots]$}

De forma inmediata acaecerá la escena del reconocimiento, cuando el Hijo de Dios se dirija a María Magdalena y, con una simple palabra, al pronunciar su nombre, ésta lo identifique como tal. Previamente -como sucede también en el Evangelio de Lucas (24: 13-31)-, hay un instante de confusión, ya que las mujeres toman al aparecido por el guardián de la tumba, lo mismo que recoge el evangelista cuando los discípulos creen que su maestro resucitado es un caminante cualquiera que se dirige hacia ellos.

Llegados a este punto, y ya que sus intervenciones serán cada vez más explicativas, es necesario subrayar que en el Noh, como sucedía en el teatro griego, el coro juega un papel fundamental. El coro del Noh lo forman de ocho a diez cantores que se sitúan arrodillados en el lado derecho del escenario. Sus intervenciones sirven para glosar al espectador qué es lo que sucede en cada momento sobre el escenario, complementando la información que dan los personajes con sus diálogos. Datos éstos que los personajes saben pero que, por su estatus o por no romper con la línea de sus parlamentos, no narran y hacen que recaiga esta misión informadora sobre el coro.

En Fukkatsu no Kirisuto se emplea a la perfección este elemento y se sabe conjugar con las alocuciones de los actores. Sirva como ejemplo otro de los momentos cumbres de la obra, el muy representado en la pintura occidental pasaje del Noli me tangere, que también recoge la pieza japonesa. Ahora bien, será el coro quien ponga en disposición al público para observar el instante con sus versos salmodiados:

[...] Saying this, they rush to Him,

Longing to touch Him,

But they are driven back

Before His glory.

Overcome with awe, they sink

To the ground at His feet. [...]

Y justo después, cuando el público tiene ya esta información a su disposición y la pone en relación con el famoso pasaje bíblico, incluso con los cuadros de Tiziano o Co- 
rreggio, el shite, Cristo resucitado, espeta fuerte y alto, tal y como nos dice la acotación pertinente:

\section{[...] Mary, do not touch Me. [...]}

Una frase que ha sembrado la controversia entre los teólogos y que muchos traducen hoy como: María, no me entretengas, sugiriendo a que en ese momento crucial el Hijo de Dios debe proclamar a todos su resurrección, dejando a un lado sus motivaciones personales. Un pasaje, por otro lado, que no aparece en ninguna de las versiones ibéricas de la Visitatio Sepulcri medievales.

Comienza ahora una segunda sección de la pieza, llena de alusiones teológicas, centrada más en el plano de la divinidad de Cristo que en el corpóreo, lo que, por otra parte, es más consecuente con su nueva y recién adquirida naturaleza. Así, ahora, una vez que sabemos quién es el shite, no extraña al espectador que desvele su idiosincrasia o su misión sobre la Tierra:

[...] I am My Father

And the Father of mankind. [...]

Y, como no podía faltar tampoco, antes de salir de escena, el shite ejecutará un lucido final de danza, luego de una intervención más del coro. Una sección fundamental de la obra, en la que los protagonistas suelen dejar unas palabras lapidarias. En este caso, las de Cristo hacia el auditorio serán:

[...] Peace be with you.

Divine grace be given unto you. [...]

Palabras que nos harán recordar el final de la misa católica. Dos pequeños versos que unen de manera ejemplar la eucaristía con lo que quiere ser, en esencia, el teatro Noh: rito. Y no hay otro rito más santificado o mayor en la tradición cristiana que el de la misa, donde se rememora el sacrifico hecho por Jesús para con su pueblo, a través de la ofrenda del pan y del vino. Tras las palabras de despedida del shite, restará el colofón del coro, una de las intervenciones más largas de toda la pieza, en la que se hará un resumen de todo lo que ha pasado sobre las tablas. En el caso que nos ocupa, frases tan directas o esclarecedoras como: He is truly resurrected se repetirán hasta en dos ocasiones.

El último verso, que acompaña la salida del actor principal de la escena, pausadamente, al ritmo que marcan las voces del coro y la música de la orquesta, quiere revelarnos qué es lo que sucederá en ese momento justo: God is returned to heaven. Y luego, silencio. 


\section{BIBLIOGRAFÍA}

Allegri, L. (1988): Teatro e spettacolo nel Medioevo. Roma-Bari: Laterza.

Bobes Naves, M. C. (2001): Semiótica de la escena. Análisis comparativo de los espacios dramáticos en el teatro europeo. Madrid: Arco/Libros.

Bowers, F. (1976 [1952]): Japanese Theatre. New York: Hermitage House.

Brandon, J. (1997): Nō and Kyogen in the contemporary world. Honolulu: Hawaii University Press.

Castro Caridad, E. (1996): Introducción al teatro latino medieval: textos y públicos. Santiago de Compostela: Servicio de publicaciones de la Universidad de Santiago de Compostela.

Castro Caridad, E. (ed.) (1997): Teatro Medieval. 1. El drama litúrgico. Barcelona: Crítica.

Díaz-Corralejo, V. (2004): Los gestos en la literatura medieval. Madrid: Gredos.

Gardini, W. (1995): Religiones y literatura de Japón. Buenos Aires: Kier.

Kakichi, K. (1981): El Zen y la Biblia: lectura corporal del koan y la Biblia. Madrid: Ediciones Paulinas.

Leonardi, C. (et al.) (2000): Diccionario de los santos, I. Madrid: Ediciones paulinas.

Taylor, R. (trad. y ed.) (1971): “'The Resurrected Christ': A Modern No Drama». En: Ariel: A Review Of International English Literature, 2, 2: http://ariel.synergiesprairies.ca/ariel/index. php/ariel/article/viewFile/558/550 (1-9-2011).

VV. AA. (2001): Dramas escolares latinos (siglos XII y XIII). Madrid: Akal.

\section{JAPONSKA SODOBNA NOH IGRA S KRŠČANSKO TEMATIKO: ¿MEŽIK IBERSKEMU SREDNJEVEŠKEMU GLEDALIŠČU?}

Ključne besede: misterij, noh, teatralizacija

Avtor članka analizira noh igro Fukkatsu no Kirisuto (Kristusovo vstajenje), ki črpa tematiko neposredno iz krščanskega izročila. Prav tako jo primerja z drugimi noh igrami z enako vsebino in poskuša razjasniti nekatere podobnosti med to obliko klasičnega japonskega gledališča in iberskim verskim gledališčem v srednjem veku (misteriji). 